\title{
Transcriptome-wide identification of optimal reference genes for expression analysis of Pyropia yezoensis responses to abiotic stress
}

\author{
Dong Gao ${ }^{1,3}$, Fanna Kong ${ }^{1,3}$, Peipei Sun ${ }^{1,3}$, Guiqi Bi ${ }^{1,3}$ and Yunxiang Mao ${ }^{1,2,3^{*}}$
}

\begin{abstract}
Background: Pyropia yezoensis, a marine red alga, is an ideal research model for studying the mechanisms of abiotic stress tolerance in intertidal seaweed. Real-time quantitative polymerase chain reaction (RT-qPCR) is the most commonly used method to analyze gene expression levels. To accurately quantify gene expression, selection and validation of stable reference genes is required.

Results: We used transcriptome profiling data from different abiotic stress treatments to identify six genes with relatively stable expression levels: MAP, ATPase, CGS1, PPK, DPE2, and FHP. These six genes and three conventional reference genes, UBC, EF1- $a$, and eif4A, were chosen as candidates for optimal reference gene selection. Five common statistical approaches (geNorm, $\Delta$ Ct method, NormFinder, BestKeeper, and ReFinder) were used to identify the stability of each reference gene. Our results show that: MAP, UBC, and FHP are stably expressed in all analyzed conditions; CGS1 and UBC are stably expressed under conditions of dehydration stress; and MAP, UBC, and CGS1 are stably expressed under conditions of temperature stress.
\end{abstract}

Conclusion: We have identified appropriate reference genes for RT-qPCR in P. yezoensis under different abiotic stress conditions which will facilitate studies of gene expression under these conditions.

Keywords: Abiotic stress, Pyropia yezoensis, Reference genes

\section{Background}

Pyropia yezoensis (Ueda), previously known as Prophyra yezoensis [1], is a seaweed of economic importance. The gametophyte of this species has been widely cultivated and harvested in East Asia. P. yezoensis is an important seafood with annual production of over 1,100,000 t (in fresh weight) and an annual value of approximately US $\$ 1.5$ billion (http://www.fao.org/fishery/statistics/en). P. yezoensis thrives in the upper intertidal zone. This is a harsh niche and during daily low tides, $P$. yezoensis is routinely exposed to high levels of light, dehydration, and extreme fluctuations in temperature and osmotic

\footnotetext{
* Correspondence: yxmao@ouc.edu.cn

${ }^{1}$ Ministry of Education, Key Laboratory of Marine Genetics and Breeding (Ocean University of China), Qingdao 266003, China

${ }^{2}$ Laboratory for Marine Biology and Biotechnology, Qingdao National Laboratory for Marine Science and Technology, Qingdao 266237, China Full list of author information is available at the end of the article
}

pressure due to the seawater to air transition. Blades can tolerate dehydration with water loss of up to $85 \%$, but are metabolically active immediately upon rehydration [2]. These features make P. yezoensis an ideal model for studying the molecular mechanisms of intertidal seaweed stress-tolerance.

Precise quantification of expression fluctuations in genes involved in abiotic stress will further our understanding of stress-tolerance mechanisms in specific algae. RT-qPCR is widely used to assess gene expression and allows rapid and reliable quantification of transcripts expressed in low levels $[3,4]$. However, for accurate quantification of transcripts in different spatial-temporal conditions, the crucial first step involves the selection of optimal reference genes. Housekeeping genes including actin $(A C T)$, ubiquitinbinding protein $(U B C)$, glyceraldehyde-3-phosphate dehydrogenase $(G A P D H)$, translation initiation factor $4 \mathrm{~A}$ 
(eif4A), elongation factor 1- $\alpha(E F 1-\alpha)$, and $\alpha$-tubulin (TUA) are thought to be appropriate reference genes for the normalization of gene expression [5-7]. However, recent investigations have shown that these housekeeping genes may not be suitable for normalization of gene expression in all development stages or environmental conditions [8-10]. Moreover, it is difficult to completely normalize gene expression data from all types of samples using any single gene $[11,12]$. Therefore, it is recommended that multiple reference genes be used to improve the reliability and accuracy of RT-qPCR results.

With the development of high-throughput sequencing technologies, RNA-sequencing (RNA-seq) provides a means to profile spatio-temporal transcriptomes [13, 14]. The rapid accumulation of transcriptome datasets presents a new strategy for the identification of novel sets of reference genes. For example, hundreds of candidates were mined from Lycoris aurea transcriptome datasets, and 14 were selected for further qPCR analysis after various abiotic stresses and from different tissues [15]. A similar approach was used to identify candidate reference genes from Oxytropis ochrocephala Bunge transcriptome datasets [16]. Twelve candidate genes were identified, and qPCR was used to analyze their expression levels following exposure to a range of abiotic stress conditions.

In $P$. yezoensis, the expression of seven housekeeping genes was quantified at different life-history stages and $G A P D H$ was recommended as a potential internal control for gene expression studies [17]. In 2015, Kong validated the expression stability of six traditional housekeeping genes and recommended ACT3, eIF4A, and EF1- $\alpha$ as optimal $P$. yezoensis reference genes under conditions of stress [18]. Recently, accumulated $P$. yezoensis transcriptome data [19-21] has enabled us to identify sets of optimal reference genes. In this study, nine candidate reference genes were chosen for further analysis and optimal reference gene selection. These genes include three conventional reference genes $(U B C$, EF1- $\alpha$, and eIF4A) and six genes (MAP, ATPase, CGS1, $P P K, D P E 2$, and $F H P$ ) with relatively stable expression levels in transcriptome profiling data obtained under different abiotic stress conditions. Further, to validate the effectiveness of the selected reference genes, the expression levels of the $\Delta 9$ fatty acid desaturase (PyOLE-1) and oxygen-evolving enhancer protein 1 (PyOEE-1) target genes were quantified and compared with transcriptome profiling data.

These two genes, PyOLE-1 and PyOEE-1, represent stress-responsive genes in algae. Under chilling and freezing temperature stress, PyOLE-1, which encodes a fatty acid desaturase, is up-regulated, to increase membrane fluidity [19]. PyOEE-1 is a component of the oxygen evolving complex of photosystem II (PSII) and is, which were slowly down-regulated under drought stress in red algae [22].
Additionally, the best and worst reference genes (selected from $P$. yezoensis RZ58) were used to normalize the expression levels of these two target genes in two other genotypes of $P$. yezoensis, including a genetically pure line ( $P$. yezoensis S21) and a cultural line (PyC-1), in order to demonstrate the applicability of our results within this species.

\section{Methods}

\section{Plant materials and treatments}

Pyropia yezoensis RZ58 is a genetically pure line established by clonal cultivation of an isolated single somatic cell and self-fertilization in the laboratory. Fresh leafy of RZ58 gametophytes were cultured in bubbling natural seawater with Provasoli's enrichment solution medium under $50 \mu \mathrm{mol}$ photons $\mathrm{m}^{-2} \mathrm{~s}^{-1}$ at $8 \pm 1{ }^{\circ} \mathrm{C}$ and a $12: 12$ light:dark (L:D) photoperiod. Then the healthy gametophytes with sizes from 8 to $15 \mathrm{~cm}$ were treated with dehydration, rehydration, and cold and heat stress respectively. The same treatments were performed in S21 and PyC-1 too.

Gametophytes were subjected to dehydration and rehydration by exposing them to the air and then transferring them back to seawater. Algal samples under normal conditions were harvested before the dehydration treatment. Algal samples were also collected when the algae reached water loss levels of $20 \pm 5 \%, 50 \pm 5 \%$ and $70 \pm$ $5 \%$ respectively. For rehydration, severely dehydrated algae were transferred back to normal conditions, and samples were collected after $0.5 \mathrm{~h}$. Water loss was determined according to the method of Kim et al. [23]. All treatments were performed at $8 \pm 1{ }^{\circ} \mathrm{C}$ and $50 \mu \mathrm{mol}$ photons $\mathrm{m}^{-2} \mathrm{~s}^{-1}$.

For subjecting gametophytes to various temperature conditions, four temperature treatments were used: normal temperature $\left(8 \pm 1{ }^{\circ} \mathrm{C}\right)$, high temperature $\left(24 \pm 1{ }^{\circ} \mathrm{C}\right)$, chilling stress $\left(0 \pm 1{ }^{\circ} \mathrm{C}\right)$ and freezing temperature $(-8 \pm$ $\left.1{ }^{\circ} \mathrm{C}\right)$. Temperature stress was detected according to Sun et al. [19]. Three biological replicates were collected for each treatment and control, frozen in liquid nitrogen, and stored at $-80{ }^{\circ} \mathrm{C}$ prior to RNA isolation.

\section{RNA isolation and CDNA synthesis}

Total RNA was extracted from samples using the Plant RNA Kit (Omega, USA). To eliminate DNA contamination, total RNA was digested with DNase I (Omega, USA) and purified according to the manufacturer's protocol. RNA integrity was evaluated by $1 \%(w / v)$ agarose gel electrophoresis, and RNA concentration and purity was determined with a NanoDrop 2000 Spectrophotometer (NanoDrop Technologies, Thermo Scientific, USA). RNA samples with concentrations above $150 \mathrm{ng} / \mu \mathrm{l}$ and an $\mathrm{A}_{260} / \mathrm{A}_{280}$ ratio of $1.8-2.0$ were used for cDNA synthesis. 
An RNA aliquot of $1 \mu \mathrm{g}$ was used for cDNA synthesis with PrimerScript ${ }^{\mathrm{Tm}}$ RT regent Kit (TaKaRa Bio Inc., Dalian, China) according to the manufacturer's protocol. The cDNA was diluted 10-fold with nuclease-free water for RT-qPCR.

Selection of candidate reference genes and primer design Due to a lack of $P$. yezoensis genome information, we generated a transcriptome for this species. Transcriptome sequencing of $P$. yezoensis (RZ58) was performed using Illumina paired-end sequencing technology on an Illumina $\mathrm{Hi}^{-\mathrm{Seq}^{\mathrm{Tm}}} 2000$ platform under the five treatments (control, dehydration, rehydration, cold, and heat). After assembly and annotation, expression profile data for each treatment was mapped to the transcriptome. The read counts of unigenes from different stress treatments were converted into fragments per kilobase of exon model per million mapped reads (FPKM values) using the RNA-Seq by Expectation Maximization software package [24].

The expression stability of each of the analyzed genes was calculated using the Pattern Gene Finder (PaGeFinder). PaGeFinder is a web-based server for the on-line detection of gene expression patterns from serial transcriptomic data generated by high-throughput technologies like microarray or next-generation sequencing. The dispersion measure (DPM) was introduced and implemented in PaGeFinder to evaluate the variability and degree of diversity of gene expression profiles. Most stable genes exhibit lower DPM values [25].

The transcriptome was screened for genes with credible protein annotation ( $\mathrm{Nr}$ databases), appropriate expression levels $(\mathrm{FPKM}>10)$, and a low dispersion measure (DPM $\leq$
0.3 ) [25]; genes that met these criteria were deemed candidate reference genes (Table 1). Additionally, three commonly used reference genes, $U B C, E F 1-\alpha$, and $e I F 4 A$, were selected from the $P$. yezoensis transcriptome based on a previous study by Kong [18].

Specific primers were designed using Primer5 software based on the sequences of these unigenes (Table 2). The criteria for primer design were as follows: primer lengths of $17-24 \mathrm{bp}, \mathrm{GC}$ content of 50$66 \%$, melting temperature of $58-61{ }^{\circ} \mathrm{C}$, and amplicon lengths of 100-200 bp.

\section{RT-qPCR analysis}

RT-qPCR was conducted in 96-well plates in a LightCycler 480 (Roche Molecular Biochemicals, Mannheim, Germany). The reaction mix contained $2 \mu$ diluted cDNA, $10 \mu \mathrm{l}$ LightCycler ${ }^{\circ} 80$ SYBR Green I Master (Roche, Germany), $0.6 \mu \mathrm{l}$ of each primer, and $\mathrm{dd}_{2} \mathrm{O}$ in a final volume of $20 \mu \mathrm{L}$. Three biological replicates were performed for each treatment. Three technical replicates of each biological replicate as well as a no-template control were also performed. RT-qPCR cycling parameters were as follows: $95{ }^{\circ} \mathrm{C}$ for $5 \mathrm{~min}$, followed by 45 cycles of $95{ }^{\circ} \mathrm{C}$ for $10 \mathrm{~s}$, $58{ }^{\circ} \mathrm{C}$ for $10 \mathrm{~s}$, and $72{ }^{\circ} \mathrm{C}$ for $20 \mathrm{~s}$. To confirm the specificity of each primer, a melting-curve analysis was included from $65{ }^{\circ} \mathrm{C}$ to $95^{\circ} \mathrm{C}$. The mean amplification efficiency of each primer pair was checked by the LightCycle ${ }^{\oplus} 480$ gene scanning software (version 1.5).

\section{Data analysis}

The three most commonly used software tools, geNorm, NormFinder, and BestKeeper, were used in conjunction

Table 1 Description of the candidate reference genes

\begin{tabular}{|c|c|c|c|c|c|c|c|}
\hline $\begin{array}{l}\text { Gene } \\
\text { symbol }\end{array}$ & Gene ID & $\begin{array}{l}\text { Gene } \\
\text { length(bp) }\end{array}$ & NR description & Accession ID & MV(FPKM) & CV & $\begin{array}{l}\text { DPM } \\
\text { (dispersion measure) }\end{array}$ \\
\hline MAP & TRINITY_DN10053_c0_g1_i1 & 1695 & $\begin{array}{l}\text { methionyl aminopeptidase } \\
\text { [Chondrus crispus] }\end{array}$ & XP_005715371.1 & 104.792 & 0.130 & 0.129 \\
\hline ATPase & TRINITY_DN1508_c0_g1_i1 & 2582 & $\begin{array}{l}\text { AAA-type ATPase } \\
\text { [Galdieria sulphuraria] }\end{array}$ & XP_005704492.1 & 36.383 & 0.136 & 0.134 \\
\hline CGS1 & TRINITY_DN3362_c1_g1_i1 & 2083 & $\begin{array}{l}\text { Cystathionine gamma-synthase, } \\
\text { Rhodoplastic CGS1 [Chondrus crispus] }\end{array}$ & XP_005718068.1 & 175.309 & 0.166 & 0.164 \\
\hline PPK & TRINITY_DN8109_c0_g1_i1 & 3034 & $\begin{array}{l}\text { polyphosphate kinase, partial } \\
\text { [Pyropia yezoensis] }\end{array}$ & CAM33394.1 & 24.197 & 0.166 & 0.164 \\
\hline DPE2 & TRINITY_DN10209_c0_g1_i1 & 2847 & $\begin{array}{l}\text { Disproportionating Enzyme type } 2 \\
\text { [Chondrus crispus] }\end{array}$ & XP_005714071.1 & 76.424 & 0.167 & 0.165 \\
\hline FHP & TRINITY_DN7986_c2_g1_i1 & 1797 & $\begin{array}{l}\text { fumarate hydratase precursor } \\
\text { [Chondrus crispus] }\end{array}$ & XP_005718019.1 & 83.279 & 0.170 & 0.168 \\
\hline UBC & TRINITY_DN9056_c0_g3_i1 & 530 & $\begin{array}{l}\text { putative ubiquitin-conjugating } \\
\text { enzyme [Pyropia yezoensis] }\end{array}$ & ACl47322.1 & 374.296 & 0.649 & $>0.3$ \\
\hline EF 1-a & TRINITY_DN9169_c0_g1_i2 & 1632 & $\begin{array}{l}\text { RecName: Full = Elongation factor } \\
\text { 1-alpha; Short }=\text { EF-1-alpha }\end{array}$ & Q8LPC4.1 & 1079.455 & 0.475 & $>0.3$ \\
\hline eif4A & TRINITY_DN16387_c0_g1_i1 & 1285 & $\begin{array}{l}\text { putative eukaryotic translation initiation } \\
\text { factor } 4 \text { A [Pyropia yezoensis] }\end{array}$ & ACJ22452.1 & 1149.390 & 0.779 & $>0.3$ \\
\hline
\end{tabular}


Table 2 Genes and primer sets for RT-qPCR

\begin{tabular}{|c|c|c|c|c|c|c|}
\hline Gene name & Gene ID & Gene symbol & $\begin{array}{l}\text { Prime sequence } \\
\text { (forward/reverse) }\end{array}$ & Size(bp) & $\begin{array}{l}\text { RT-qPCR } \\
\text { Efficiency }^{\mathrm{a}}\end{array}$ & Error $^{b}$ \\
\hline \multirow[t]{2}{*}{ Methionyl aminopeptidase } & \multirow[t]{2}{*}{ TRINITY_DN10053_C0_g1_i1 } & \multirow[t]{2}{*}{ MAP } & TGGGTAGGAAGTGGGGCT & \multirow[t]{2}{*}{200} & \multirow[t]{2}{*}{1.946} & \multirow[t]{2}{*}{0.0793} \\
\hline & & & CGTGGTAGGTCGGTAGGC & & & \\
\hline \multirow[t]{2}{*}{ AAA-type ATPase } & \multirow[t]{2}{*}{ TRINITY_DN1508_c0_g1_i1 } & \multirow[t]{2}{*}{ ATPase } & CGACGAGATTGACGCA & \multirow[t]{2}{*}{132} & \multirow[t]{2}{*}{2.014} & \multirow[t]{2}{*}{0.0744} \\
\hline & & & GTCGCCCCAATCACAA & & & \\
\hline \multirow{2}{*}{$\begin{array}{l}\text { Cystathionine gamma-synthase, } \\
\text { Rhodoplastic }\end{array}$} & TRINITY_DN3362_c1_g1_i1 & CGS1 & CTACGGACACCAAGAAACG & \multirow[t]{2}{*}{106} & \multirow[t]{2}{*}{1.947} & \multirow[t]{2}{*}{0.121} \\
\hline & & & CTCGGTTGGCTGGGTAA & & & \\
\hline \multirow[t]{2}{*}{ polyphosphate kinase, partial } & \multirow[t]{2}{*}{ TRINITY_DN8109_C0_g1_i1 } & \multirow[t]{2}{*}{ PPK } & GTGTCTGGTCCACGCTC & \multirow[t]{2}{*}{160} & \multirow[t]{2}{*}{1.98} & \multirow[t]{2}{*}{0.101} \\
\hline & & & CACGAGGTGCTGACTGAG & & & \\
\hline \multirow[t]{2}{*}{ Disproportionating Enzyme type 2} & \multirow[t]{2}{*}{ TRINITY_DN10209_C0_g1_i1 } & \multirow[t]{2}{*}{ DPE2 } & CACGGAAGGTAGGAAAGGA & \multirow[t]{2}{*}{204} & \multirow[t]{2}{*}{1.992} & \multirow[t]{2}{*}{0.0582} \\
\hline & & & AGGTGGGTGTTGGGGTT & & & \\
\hline \multirow[t]{2}{*}{ fumarate hydratase precursor } & \multirow[t]{2}{*}{ TRINITY_DN7986_c2_g1_i1 } & \multirow[t]{2}{*}{$\mathrm{FHP}$} & TAATGTGCGAAAAGGCGG & \multirow[t]{2}{*}{146} & \multirow[t]{2}{*}{1.973} & \multirow[t]{2}{*}{0.117} \\
\hline & & & CGTGAACAAGTCCCAGTCCT & & & \\
\hline \multirow[t]{2}{*}{ ubiquitin-conjugating enzyme } & \multirow[t]{2}{*}{ TRINITY_DN9056_C0_g3_i1 } & UBC & CGCTGACCGTTTCCAAG & 112 & 1.99 & 0.0598 \\
\hline & & & CGACTGCGGTTGGACTT & & & \\
\hline elongation factor & TRINITY_DN9169_C0_g1_i2 & $\mathrm{EF}$ & TGCGAGTCAACCAGGAG & 175 & 1.96 & 0.153 \\
\hline & & & GCCTCAAGAAACACCCTA & & & \\
\hline translation initiation factor $4 \mathrm{~A}$ & TRINITY_DN16387_C0_g1_i1 & eif4A & ATGGACCAGAAGGACCG & 139 & 1.951 & 0.144 \\
\hline & & & TCGTGGGCAGGTCATAG & & & \\
\hline
\end{tabular}

a The RT-qPCR amplification efficiency for each primer were determined by LightCycle ${ }^{\circledR} 480$ gene scanning software (version 1.5 )

${ }^{b}$ The Error value of amplification efficiency for each primer were determined by LightCycle ${ }^{\oplus} 40$ gene scanning software (version 1.5 ) and an acceptable vaule should be $<0.2$

with the comparative $\Delta \mathrm{Ct}$ method to calculate and identify the expression level stability of each candidate reference gene.

The geNorm algorithm [26] calculates the expression stability value (M-value) and pairwise variation $(\mathrm{Vn} / \mathrm{n}+$ 1) for all candidate genes. Lower $M$-values reflect a greater level of gene expression stability. The $\mathrm{Vn} / \mathrm{n}+1$ value determines the optimal number of reference genes for accurate normalization. A cut-off value of $\mathrm{Vn} / \mathrm{n}+1<$ 0.15 indicates that an additional reference genes make no significant contribution to the normalization.

The NormFinder program [27] is based on an ANOVA model, and calculates a stability value (SV) for evaluating expression variation when using reference genes for normalization with a lower SV indicating higher stability.

BestKeeper [28] is an Excel-based tool that uses pairwise correlations. BestKeeper calculates three variables for the expression level of all candidate genes: the standard deviation, coefficient of correlation (r), and coefficient of variance $(\mathrm{CV})$. The BestKeeper index is established based on the combination of the mean of $\mathrm{Ct}$ values for each sample across all candidate genes. Subsequently, each candidate gene is tested in a pair-wise manner via Pearson correlation coefficients, the coefficient of determination $\left(\mathrm{r}^{2}\right)$, and the $P$-value. The most stable gene exhibits the lowest $\mathrm{CV} \pm \mathrm{SD}$ (standard deviation) value, and genes with an SD value greater than one are deemed unacceptable and should be excluded.

The comparative $\Delta \mathrm{Ct}$ method depends on pairwise comparisons [29], which calculate the mean and SD of each pair candidate genes and the average SD of each gene. The gene with lowest average SD is considered the most stable reference gene.

\section{Comprehensively ranking the candidate genes}

A comprehensive stability value for each gene was produced using ReFinder (http://150.216.56.64/referencegene.php) [30] based on the four computational programs, NormFinder, BestKeeper, GeNorm, and comparative $\Delta \mathrm{Ct}$. The $\mathrm{Ct}$ value of each gene was input directly and the geometric mean of each gene was calculated to arrive at its overall final ranking. A lower geometric mean of ranking value indicates more stable expression.

\section{Experimental validation of the reference genes}

The expression patterns of the two target genes PyOLE1 and $P y O E E-1$ were analyzed using the most and least stable reference gene sets after normalization across two experimental sets temperature stress (for PyOLE-1) and drought stress (for PyOEE-1). To validate the results, the expression levels of the target genes based on RT-qPCR 
were compared with the FPKM values derived from the RNA-seq data for each sample. Moreover, the relative expression levels of each target gene were compared using a single reference gene as well as the most stable reference genes to determine whether the inclusion of multiple reference genes improves the reliability and accuracy of RT-qPCR results.

Finally, we also quantified the expression patterns of these target genes in two another genotypes of $P$. yezoensis (S21 and PyC-1) using the most and least stable reference gene sets.

\section{Results}

\section{Global transcriptome assembly and function annotation}

A total of $1.72 \times 10^{7}$ quality paired-end reads were obtained after filtering out low-quality data (tags containing adaptors). The GC content of the transcriptome was $67.74 \%$. After assembly and annotation, a total of 19,643 unigenes with a mean length of 779.5 bp and an N50 value of 1149 bp were obtained. To assign accurate annotation information to all unigenes, the NCBI nonredundant protein $(\mathrm{Nr})$ database was interrogated, and a total of 13,160 unigenes (67\%) were annotated.

\section{Selection of candidate reference genes in $P$. yezoensis and specificity and efficiency of PCR amplification}

As shown in Additional file 1: Figure S1, the expression stabilities of all transcripts were evaluated by PaGeFinder the results showed that only 2060 unigenes (326 unigenes marked by asterisk whose DPM values were lower than 0.2 and all of novel reference genes derived from them; the DPM value of 1734 unigenes were located in the range from 0.2 to 0.3 ) can be used to further reference genes selection $(\mathrm{DPM}<0.3)$. Then, we removed some transcripts which did not have a credible function annotation or whose expression level is too low (FPKM $<$ 10) $[15,16]$. Finally, 865 unigenes were retained.

MAP, ATPase, CGS1, PPK, DPE2, and FHP were selected from these unigenes based on the ranked order of the DPM values from smallest to largest. Three commonly used reference genes, $U B C, E F 1-\alpha$, and eif $4 A$, were selected from the transcriptome directly [19].

Primers were designed for each of the nine genes and their specificities were confirmed by agarose gel electrophoresis, and melting curves analysis, which showed single amplicon of the expected size and single peak melting curve (Additional file 2: Figure S2). Meanwhile, we also sequenced all PCR products to ensure that only the intended target was being amplified (Table 2). RT-qPCR products ranged from 137 to $213 \mathrm{bp}$ and the mean PCR efficiency for each gene ranged from 1.946 to 2.014 .

\section{Cq values of candidate reference genes}

RNA transcript levels of the nine reference genes were assessed in conditions of dehydration and temperature stress. The raw $\mathrm{Cq}$ values for the reference genes are shown in Additional file 3: Figure S3.

According to the summary showed in Additional file 3: Figure S3A, the raw Cq values of dehydration samples were between 18.90 and 33.28 for $U B C$ and eif $4 A$, respectively. Mean $C q$ values ranged from 20.04 to 26.79 for $U B C$ and $P P K$, respectively. $M A P, P P K$, and DPE2 had low expression levels with high $\mathrm{Cq}$ values, and CGS1, FHP, and eif $4 A$ showed moderate expression levels. UBC, EF1- $\alpha$, and ATPase demonstrated high expression levels with low $\mathrm{Cq}$ values $(20.04,20.88$, and 23.13 respectively). The SDs of the Cq values for UBC $(20.04 \pm 0.27)$ and CGS1 $(24.82 \pm 0.16)$ were much lower than those of DPE2 $(25.26 \pm 0.97)$ and eif4A (23.95 \pm 0.99$)$. Under temperature stress, the raw $\mathrm{Ct}$ values ranged from 17.80 to 31.53 for $U B C$ and $D P E 2$, respectively (Additional file 3: Figure S3B). Of the nine candidate reference genes, CGS1, PPK, and DPE2 were observed to have the lowest expression levels with Ct values of 25.84, 25.36, and 28.56, respectively. Ct values for ATPase, UBC, and $E F 1-\alpha$ were $21.54,20.00$, and 21.12, respectively, indicating that transcripts of these genes were abundant in samples under temperature stress. The least variable reference genes were $M A P$ and ATPase with SD values of 0.29 and 0.47, respectively. Conversely, DPE2 and eif4A were the most variable genes with SD values of 1.30 and 1 . 53 , respectively.

\section{Expression stability of candidate reference genes}

To identify optimal reference genes for the experimental conditions used, four statistical approaches were employed. The M-values of nine reference genes were calculated and the stability of each candidate reference gene was ranked by the $\mathrm{M}$-value calculated using geNorm. Genes with the lowest M-values are considered to have the most stable expression with an M-value less than 0.5 denoting stable gene expression [31]. geNorm analysis showed that CGS1 and FHP shared the lowest M-value of 0.219 , and were regarded as the best reference genes for dehydration stress (Additional file 4: Figure S4A). Under conditions of temperature stress, MAP and ATPase were the reference genes with the greatest expression stability (Additional file 4: Figure S4B). When considering all treatments, the M-based ranking of the reference genes examined, from most (lowest $M$ value) to least stable (highest $M$ value), was: $M A P, U B C, F H P, E F 1-\alpha$, CGS1, ATPase, PPK, eifA, and DPE2 (Table 3 and Additional file 4: Figure S4C).

In the dehydration stress subset, the V2/3 value was 0 . 115 , suggesting that two reference genes should be used for normalization. In the temperature stress subset, the V3/4 value was lower than 0.15 indicating that only three 
Table $\mathbf{3}$ geNorm ranking for the 9 candidate reference genes

\begin{tabular}{|c|c|c|c|c|c|c|}
\hline \multirow[t]{2}{*}{ Rank } & \multicolumn{2}{|c|}{ All stress } & \multicolumn{2}{|c|}{ Dehydration stress } & \multicolumn{2}{|c|}{ Temperature stress } \\
\hline & Gene & M value & Gene & $M$ value & Gene & $M$ value \\
\hline 1 & MAP & 0.478 & CGS1 & 0.219 & MAP & 0.485 \\
\hline 2 & UBC & 0.478 & FHP & 0.219 & ATPase & 0.485 \\
\hline 3 & FHP & 0.592 & PPK & 0.314 & EF1-a & 0.544 \\
\hline 4 & EF1-a & 0.646 & UBC & 0.357 & UBC & 0.583 \\
\hline 5 & CGS1 & 0.744 & MAP & 0.466 & CGS1 & 0.628 \\
\hline 6 & PPK & 0.904 & $E F 1-a$ & 0.566 & $\mathrm{FHP}$ & 0.65 \\
\hline 7 & ATPase & 1 & eif4A & 0.67 & PPK & 0.868 \\
\hline 8 & eif4A & 1.111 & DPE2 & 0.79 & DPE2 & 1.045 \\
\hline 9 & DPE2 & 1.376 & ATPase & 0.895 & eif4A & 1.188 \\
\hline
\end{tabular}

$M$ value: expression stability value

reference genes were necessary. Additionally, when all samples were considered, the pairwise variation $\mathrm{V} 3 / 4$ value was the lowest (0.153) but still above 0.15 (Additional file 5: Figure S5 and Additional file 6: Table S1).

Based on normalization factor calculation, NormFinder ranked the candidate reference genes according to their minimal combined inter- and intra-treatment expression variation. According to the stability value calculated with the NormFinder algorithm, $U B C$, CGS1, and FHP were the most reliable references genes for dehydration treatments, and $U B C, M A P$, and CGS1 were the optimal reference genes for conditions of heat and cold stress. When both dehydration and temperature treatments were considered together, the three most reliable reference genes were $U B C, M A P$ and EF1- $\alpha$ with stability values of 0.254 , 0.373 and 0.406 respectively (Table 4 ).

BestKeeper analysis determined stable reference gene candidates based on the $\mathrm{Ct}$ values of each gene, SD, and CV. Genes with a SD greater than one are considered unstable. Under conditions of dehydration stress CGS1 $(0.63 \pm 0.16)$ and FHP $(0.67 \pm 0.16)$ were the most stable genes. While under conditions of temperature stress, MAP, ATPase, and $U B C$ were the most suitable reference genes. Combining all abiotic stress treatment conditions revealed that $U B C, M A P$, and $F H P$ had $C V$ \pm SD values of $1.68 \pm 0.43,2.08 \pm 0.41$, and $2.04 \pm 0.49$ respectively, and were regarded as the most appropriate reference genes for normalization (Table 5).

By comparing the differential expression of 'gene pairs', the $\Delta \mathrm{Ct}$ method identifies stably co-expressed gene pairs when the $\Delta \mathrm{Ct}$ value of two genes remains constant across different samples [32]. The boxplot of $\Delta \mathrm{Ct}$ values for each 'gene pair' is shown in Additional file 7: Figure S6. Table 6, the results showed that $U B C$ (mean $\mathrm{SD}=0.948$ ), $M A P$ (mean $\mathrm{SD}=1.009$ ), and FHP (mean $\mathrm{SD}=1.048$ ) were the most reliable reference genes under all analyzed conditions;
Table 4 Expression stability of the 9 candidate reference genes calculated by NormFinder

\begin{tabular}{|c|c|c|c|c|c|c|}
\hline \multirow[t]{2}{*}{ Rank } & \multicolumn{2}{|c|}{ All stress } & \multicolumn{2}{|c|}{ Dehydration stress } & \multicolumn{2}{|c|}{ Temperature stress } \\
\hline & Gene & Stability & Gene & Stability & Gene & Stability \\
\hline 1 & UBC & 0.254 & UBC & 0.209 & UBC & 0.173 \\
\hline 2 & MAP & 0.373 & CGS1 & 0.257 & MAP & 0.293 \\
\hline 3 & EF1-a & 0.406 & FHP & 0.315 & CGS1 & 0.402 \\
\hline 4 & FHP & 0.408 & MAP & 0.342 & EF1-a & 0.424 \\
\hline 5 & CGS1 & 0.491 & $E F 1-a$ & 0.365 & ATPase & 0.476 \\
\hline 6 & PPK & 0.708 & PPK & 0.370 & FHP & 0.505 \\
\hline 7 & eif4A & 0.761 & eif4A & 0.527 & DPE2 & 0.718 \\
\hline 8 & ATPase & 0.783 & DPE2 & 0.589 & PPK & 0.847 \\
\hline 9 & DPE2 & 1.246 & ATPase & 0.646 & eif4A & 0.972 \\
\hline
\end{tabular}

$U B C$ and CGS1 are stably expressed under conditions of dehydration stress; and $U B C, M A P$, and ATPase are stably expressed under conditions of temperature stress with mean SD values of $0.885,0.886$ and 0.920 respectively.

\section{Comprehensive stability analysis of reference genes}

ReFinder integrates the four statistical approaches used to compare and rank the candidate reference genes. In all abiotic stress treatments, ReFinder ranked the candidate reference genes from the highest to the lowest stability as: $U B C>M A P>F H P>E F 1-\alpha>C G S 1>$ ATPase $>$ eif4A > DPE2 (Table 7). Under conditions of temperature stress, $M A P, U B C$, and CGS1 were the three most stable reference genes analyzed, while under dehydration stress the most stable reference genes were CGS1, followed by $U B C$ and $F H P$. The overall ranking showed that $U B C$ and $M A P$ were the most reliable reference genes in all different abiotic stress conditions, while DPE2 and eif4A were the least reliable.

Table 5 Expression stability of 9 candidate reference genes calculated by BestKeeper

\begin{tabular}{|c|c|c|c|c|c|c|c|c|c|}
\hline \multirow[t]{2}{*}{ Rank } & \multicolumn{3}{|c|}{ All stress } & \multicolumn{3}{|c|}{ Dehydration stress } & \multicolumn{3}{|c|}{ Temperature stress } \\
\hline & Gene & SD & CV & Gene & SD & CV & Gene & SD & CV \\
\hline 1 & MAP & 0.43 & 1.68 & CGS1 & 0.16 & 0.63 & MAP & 0.29 & 1.16 \\
\hline 2 & UBC & 0.41 & 2.08 & $\mathrm{FHP}$ & 0.16 & 0.67 & ATPase & 0.47 & 2.19 \\
\hline 3 & FHP & 0.49 & 2.04 & PPK & 0.27 & 1 & UBC & 0.52 & 2.68 \\
\hline 4 & PPK & 0.67 & 2.55 & UBC & 0.27 & 1.39 & CGS1 & 0.74 & 2.86 \\
\hline 5 & CGS1 & 0.69 & 2.74 & MAP & 0.5 & 1.94 & PPK & 0.75 & 2.93 \\
\hline 6 & EF1-a & 0.7 & 3.34 & $\mathrm{EF} 1-\mathrm{a}$ & 0.68 & 3.28 & EF1-a & 0.69 & 3.28 \\
\hline 7 & ATPase & 0.81 & 3.6 & DPE2 & 0.97 & 3.86 & FHP & 0.88 & 3.71 \\
\hline 0 & eif4A & 1.17 & 5.07 & ATPase & 0.98 & 4.28 & DPE2 & 1.3 & 4.57 \\
\hline 9 & DPE2 & 1.68 & 6.34 & eif4A & 0.99 & 4.27 & eif4A & 1.53 & 6.69 \\
\hline
\end{tabular}


Table 6 Expression stability of 9 candidate reference genes calculated by $\Delta \mathrm{Ct}$ method

\begin{tabular}{|c|c|c|c|c|c|c|}
\hline \multirow[t]{2}{*}{ Rank } & \multicolumn{2}{|c|}{ All stress } & \multicolumn{2}{|c|}{ Dehydration stress } & \multicolumn{2}{|c|}{ Temperature stress } \\
\hline & Gene & MeanSD & Gene & MeanSD & Gene & MeanSD \\
\hline 1 & UBC & 0.948 & UBC & 0.573 & UBC & 0.885 \\
\hline 2 & MAP & 1.009 & CGS1 & 0.596 & MAP & 0.886 \\
\hline 3 & FHP & 1.048 & FHP & 0.666 & ATPase & 0.920 \\
\hline 4 & EF1-a & 1.079 & MAP & 0.680 & EF1-a & 0.935 \\
\hline 5 & CGS1 & 1.190 & PPK & 0.739 & CGS1 & 0.945 \\
\hline 6 & ATPase & 1.347 & EF1-a & 0.799 & $\mathrm{FHP}$ & 1.019 \\
\hline 7 & eif4A & 1.435 & eif4A & 0.852 & DPE2 & 1.636 \\
\hline 8 & PPK & 1.495 & ATPase & 1.050 & PPK & 1.681 \\
\hline 9 & DPE2 & 2.338 & DPE2 & 1.073 & eif4A & 1.702 \\
\hline
\end{tabular}

\section{Reference genes validation}

Under conditions of temperature stress, at $24{ }^{\circ} \mathrm{C}, 0{ }^{\circ} \mathrm{C}$, and $-8{ }^{\circ} \mathrm{C}$, PyOLE-1 expression was up-regulated 1.50 fold, 4.05-fold, and 10.28-fold respectively, when using the most stable reference genes (MAP, UBC, and CGS1). Using the least stable reference genes, $P P K, D P E 2$, and eif $4 A$, resulted in overestimation of $P y O L E-1$ expression was overestimated at 5.97-fold, 18.78-fold, and 39.76fold for conditions of $24{ }^{\circ} \mathrm{C}, 0{ }^{\circ} \mathrm{C}$, and $-8{ }^{\circ} \mathrm{C}$, respectively (Fig. 1a, b, c). Similarly, under conditions of dehydration, with water loss rates of $20 \%, 50 \%$, and $70 \%$, PyOEE- 1 expression was down-regulated 0.81 -fold, 0.96-fold, and 0 . 82 -fold, respectively, when normalized using the two stable genes (CGS1 and $U B C)$. In contrast, the expression levels of $P y O E E-1$ were up-regulated 3.80fold, 7.72-fold, and 7.63-fold respectively, when the least stable reference genes (ATPase and DPE2) were used (Fig. 2a, b, c). Next, we compared these RT-qPCR results with those derived from the RNA-seq-based expression profiling. As shown in Fig. 3, the relative expression levels of PyOLE-1 quantified by the best reference genes were more consistent with the RNA-seq-based expression patterns of $P y O L E-1$ under temperature stress (upregulated 1.03 fold, 4.19 fold and 6.50 fold). Under drought conditions, the RT-qPCR results, when normalized by the best reference genes, were also more similar to the RNA-seq-based results (down-regulated 0.63 fold, 0.60 fold and 0.67 fold). Furthermore, we compared the difference between the relative expression levels when using a single reference gene and those obtained using the best reference genes. Under conditions of temperature stress, similar PyOLE-1 expression levels were observed when either a single reference gene or multiple reference genes were used (Fig. 4). At $24{ }^{\circ} \mathrm{C}, 0^{\circ}$ $\mathrm{C}$ and $-8{ }^{\circ} \mathrm{C}$, when only $M A P$ was used as a reference gene, the relative expression of PyOLE-1 was upregulated by 1.17 -fold, 4.21 -fold and 10.92 -fold respectively. Similarly, PyOLE-1 was up-regulated by 1.56 -fold, 4.05-fold and 10.28-fold respectively, when several stable reference genes (MAP, UBC and CGS1) were employed to calculate the relative expression of PyOLE-1. Under conditions of $20 \%, 50 \%$ and $70 \%$ dehydration, however, the $P y O E E-1$ expression levels were down regulated by 0.72 -fold, up-regulated 1.36 -fold, and 1.21-fold when

Table 7 Comprehensive ranking of the expression stability of 9 candidate reference genes

\begin{tabular}{|c|c|c|c|c|c|c|c|c|c|}
\hline Method & 1 & 2 & 3 & 4 & 5 & 6 & 7 & 8 & 9 \\
\hline \multicolumn{10}{|c|}{ A.RANKING ORDER UNDER ALL STRESS(BETTER-GOOD-AVERAGE) } \\
\hline geNorm & MAP/UBC & & $\mathrm{FHP}$ & EF 1-a & CGS1 & PPK & ATPase & eif4A & DPE2 \\
\hline NormFinder & UBC & MAP & $E F 1-a$ & FHP & CGS1 & PPK & eif4A & ATPase & DPE2 \\
\hline BestKeeper & MAP & UBC & $\mathrm{FHP}$ & PPK & CGS1 & EF 1-a & ATPase & eif4A & DPE2 \\
\hline$\Delta$ ct method & UBC & MAP & FHP & EF 1-a & CGS1 & ATPase & eif4A & PPK & DPE2 \\
\hline Comprehensive ranking & UBC & MAP & FHP & EF 1-a & CGS1 & PPK & ATPase & eif4A & DPE2 \\
\hline \multicolumn{10}{|c|}{ B.RANKING ORDER UNDER DEHYDRATION STRESS (BETTER-GOOD-AVERAGE) } \\
\hline geNorm & CGS1/FHP & & PPK & UBC & MAP & EF 1-a & eif4A & DPE2 & ATPase \\
\hline NormFinder & UBC & CGS1 & $\mathrm{FHP}$ & MAP & EF 1-a & PPK & eif4A & DPE2 & ATPase \\
\hline BestKeeper & CGS1 & FHP & PPK & UBC & MAP & EF 1-a & DPE2 & ATPase & eif4A \\
\hline$\Delta \mathrm{ct}$ method & UBC & CGS1 & FHP & MAP & PPK & EF 1-a & eif4A & ATPase & DPE2 \\
\hline Comprehensive ranking & CGS1 & UBC & FHP & PPK & MAP & EF 1-a & eif4A & DPE2 & ATPase \\
\hline \multicolumn{10}{|c|}{ C.RANKING ORDER UNDER TEMPERATURE STRESS (BETTER-GOOD-AVERAGE) } \\
\hline geNorm & MAP/ATPase & & EF 1-a & UBC & CGS1 & $\mathrm{FHP}$ & PPK & DPE2 & eif4A \\
\hline NormFinder & UBC & MAP & CGS1 & EF 1-a & ATPase & FHP & DPE2 & PPK & eif4A \\
\hline BestKeeper & MAP & ATPase & UBC & CGS1 & PPK & EF 1-a & FHP & DPE2 & eif4A \\
\hline$\Delta$ ct method & UBC & MAP & ATPase & EF 1-a & CGS1 & $\mathrm{FHP}$ & DPE2 & PPK & eif4A \\
\hline Comprehensive ranking & MAP & UBC & CGS1 & ATPase & EF 1-a & $\mathrm{FHP}$ & PPK & DPE2 & eif4A \\
\hline
\end{tabular}



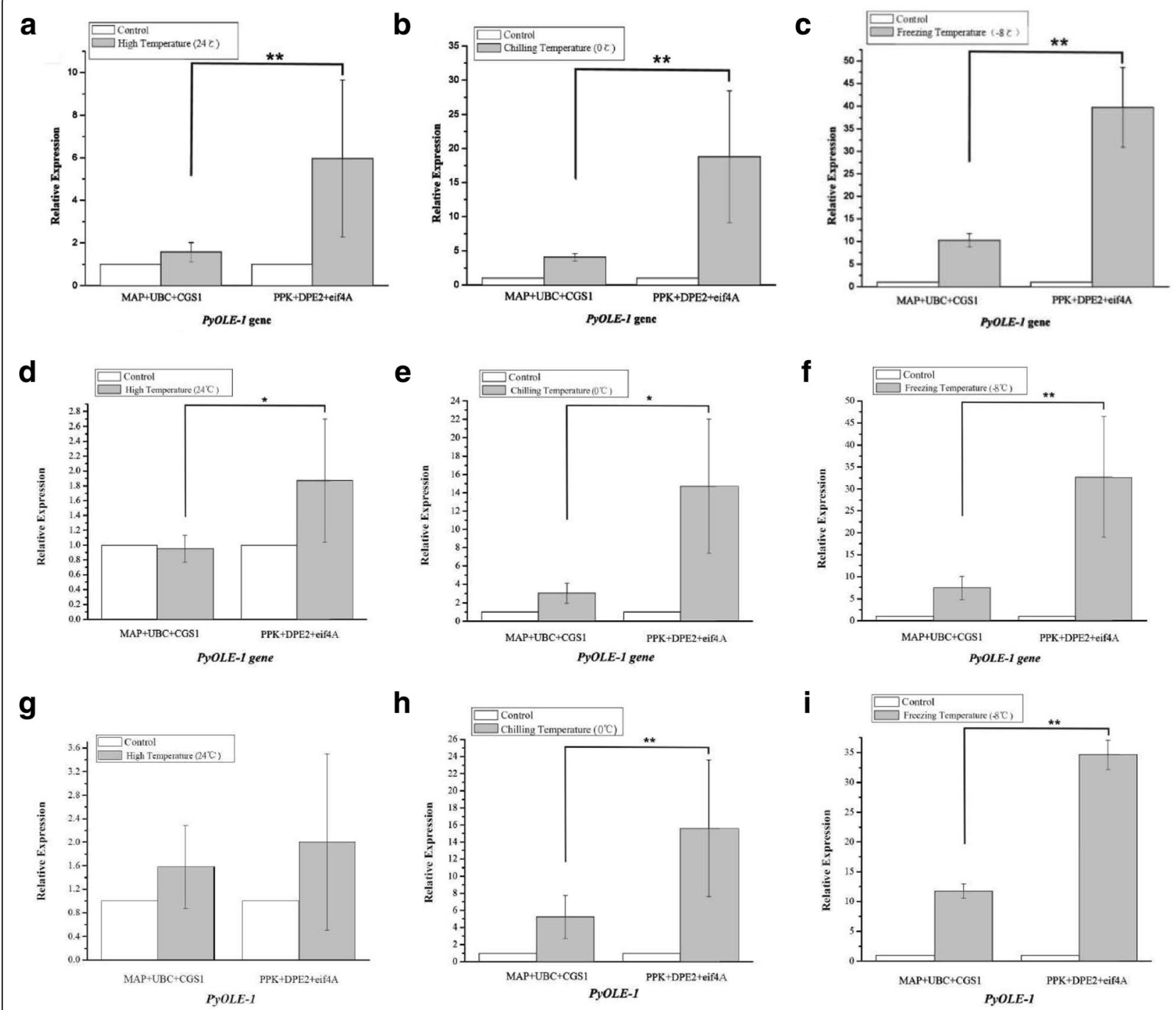

Fig. 1 Normalized expression level of PyOLE-1 gene in different genotypes in temperature stress. $(\mathbf{a}, \mathbf{b}$, $\mathbf{c})$ Relative quantification of PyOLE-1 gene expression using the best stable reference genes (MAP, UBC and CGS1) and the least stable genes (PPK, DPE2 and eif4A) under temperature stress in RZ58. $\mathbf{d}, \mathbf{e}, \mathbf{f}$ Relative quantification of PyOLE-1 gene expression using the best stable reference genes (MAP, UBC and CGS1) and the least stable genes (PPK, DPE2 and eif4A) under temperature stress in S21. $\mathbf{g}, \mathbf{h}, \mathbf{i}$ Relative quantification of PyOLE-1 gene expression using the best stable reference genes (MAP, UBC and CGS1) and the least stable genes (PPK, DPE2 and eif4A) under temperature stress in PyC-1. The average Ct value was calculated from three biological and technical replicates and used for relative expression analyses. Error bars indicate standard errors. The statistical significance was showed by one or two asterisks ( $P$ value is lower than 0.05 or 0.01 ) respectively

using a single reference gene (CGS1), while relative expression levels of PyOEE-1 were down-regulated: 0.81fold, 0.96-fold and 0.82-fold respectively, when CGS1 and $U B C$ were both used as reference genes (Fig. 5). Additionally, to confirm whether our reference genes could be applied to other experimental models of $P$. yezoensis under the same abiotic stress conditions, two other genotypes of this species (S21 and $\mathrm{PyC}-1)$ were treated with the same temperature and drought stress like conditions as RZ58. Then, we used the most and lest stable reference genes (MAP, UBC, CGS1, PPK, $D P E 2$ and eif $4 A$ for temperature conditions and CGS1,
$U B C, D P E 2$ and ATPase for dehydration conditions) to normalize the relative expression levels of $P y O L E-1$ and PyOEE-1.

For temperature stress, the similar with RZ58, relative expression levels of $P y O L E-1$ were observed in S21 and PyC-1 (Fig. 1d, e, f and g, h, i), when the best reference genes were used for quantification. In S21, PyOLE-1 was up regulated: 1.58 -fold, 5.25 -fold and 11.74-fold at $24^{\circ}$ $\mathrm{C}, 0{ }^{\circ} \mathrm{C}$, and $-8{ }^{\circ} \mathrm{C}$, respectively, while, in PyC-1, PyOLE1 was up-regualted 0.95 -fold, 3.03 -fold and 7.45 -fold, respectively. In contrast, the expression level of PyOLE-1 was overestimated by 2.03 -fold, 15.58 -fold and 34.62 - 

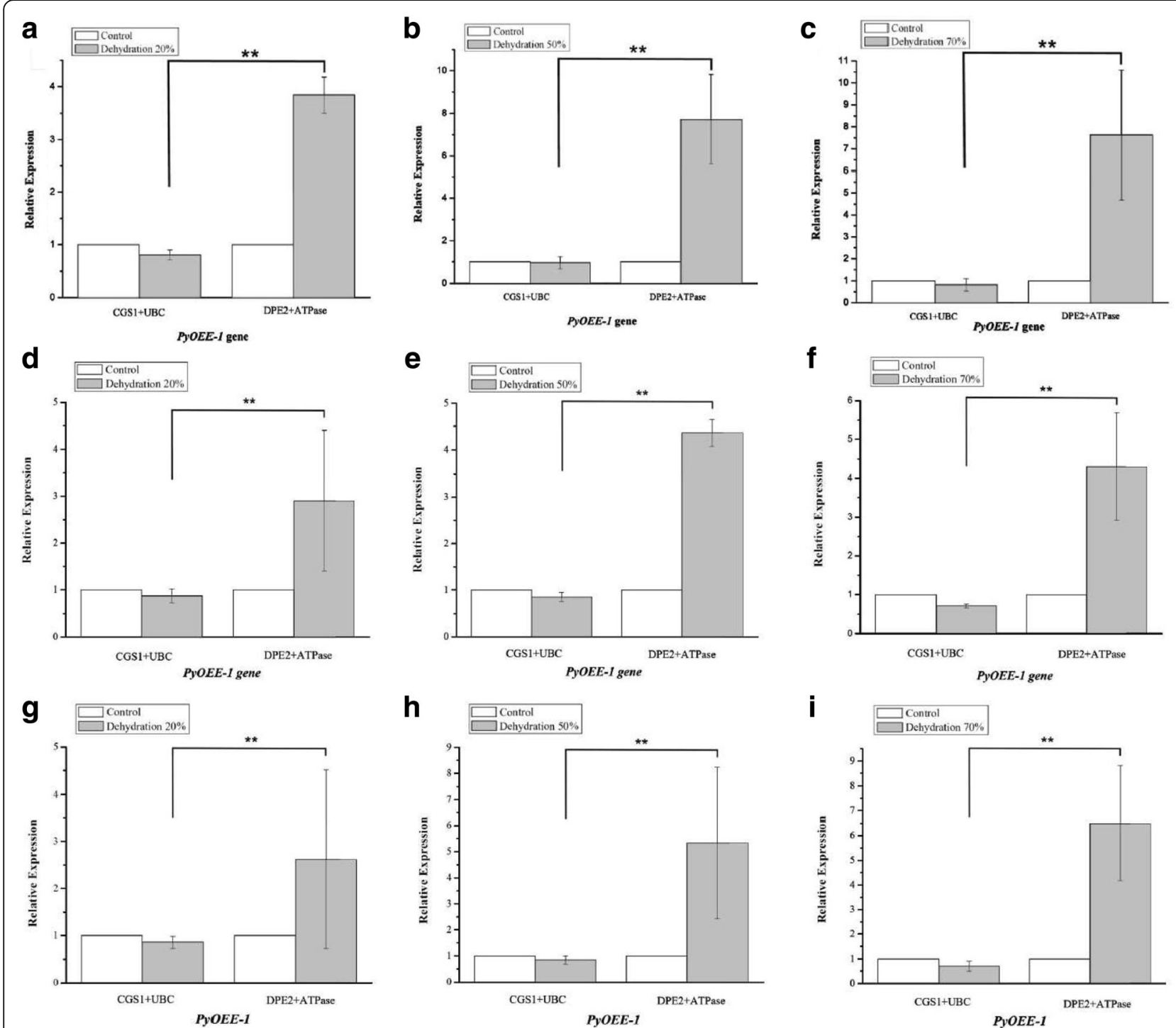

Fig. 2 Normalized expression level of PyOEE-1 gene in different genotypes in dehydration stress. (a, b, c) Relative quantification of PyOEE-1 gene expression using the best stable reference genes (CGS1 and UBC) and the least stable genes (DPE2 and ATPase) under dehydration stress in RZ58. $\mathbf{d}, \mathbf{e}$, $\mathbf{f}$ Relative quantification of PyOEE-1 gene expression using the best stable reference genes (CGS1 and UBC) and the least stable genes (DPE2 and ATPase) under dehydration stress in S21. $\mathbf{g}, \mathbf{h}$, i Relative quantification of PyOEE-1 gene expression using the best stable reference genes (CGS1 and UBC) and the least stable genes (DPE2 and ATPase) under dehydration in PyC-1. The average Ct value was calculated from three biological and technical replicates and used for relative expression analyses. Error bars indicate standard errors. The statistical significance was showed by one or two asterisks ( $P$ value is lower than 0.05 or 0.01 ) respectively

fold respectively, in $\mathrm{PyC}-1$ when the least stable reference genes were used.

Under conditions of drought, with water loss rates of $20 \%$, $50 \%$ and $70 \%, P y O E E-1$ was down-regulated 0.87 -fold, 0.85 fold and 0.71-fold in S21 and 0.87-fold, 0.85-fold and 0.70fold in PyC-1, respectively (Fig. 2d, e, f and g, h, i) when the best reference genes were used. Using the worst reference genes, however, the expression levels of PyOEE-1 were upregulated at 2.94-fold, 4.36-fold and 4.30-fold in S21 and 2. 62-fold, 5.33-fold and 6.50-fold in PyC-1, respectively.

\section{Discussion}

RT-qPCR is a highly sensitive technique used in a wide range of applications. Therefore, the selection and use of suitable reference genes is a prerequisite for the accurate quantification of gene expression levels. Based on current researches, transcriptomic profile data is a reliable source for exploration of suitable reference genes for specific experimental conditions [15, 16, 33]. In this study, six candidate reference genes were selected from transcriptome of $P$. yezoensis by some criteria including 

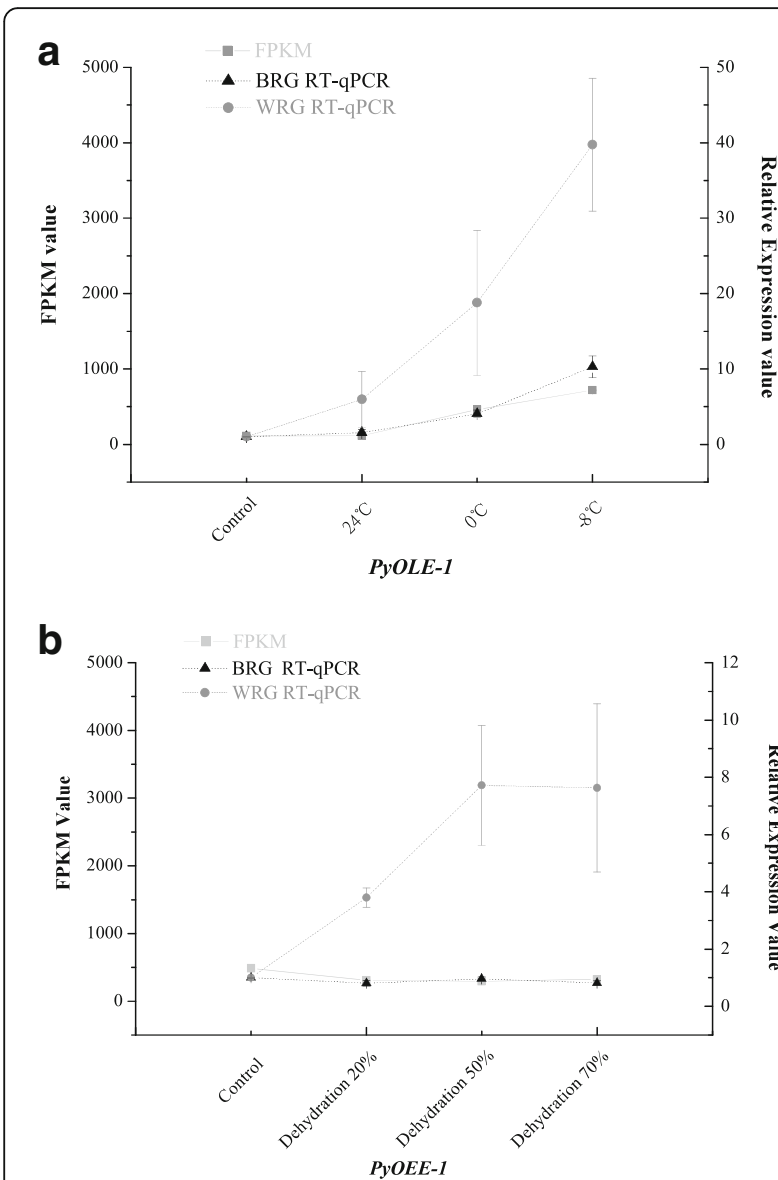

Fig. 3 Comparison of normalized expression level of target genes in RT-qPCR and FPKM value under temperature and dehydration stress respextively. (a) For temperature conditions, FPKM values of PyOLE-1 were showed in this figure and evaluated it by the $Y$-axis of left, and the right $Y$-axis were used to indicate the relative quantifications of PyOLE-1, normalized by the most stable reference genes (MAP, UBC and CGS1) and the worst stable reference genes (PPK, DPE2 and eif4A). $\mathbf{b}$ For dehydration conditions, FPKM values of PYOEE-1 were showed in this figure and evaluated it by the $Y$-axis of left, and the right $Y$-axis were used to indicate the relative quantifications of PYOEE-1, normalized by the most stable reference genes (CGS1 and $U B C$ ) and the worst stable reference genes (DPE2 and ATPase)

credible protein annotation ( $\mathrm{Nr}$ databases), appropriate expression levels (FPKM $>10)$, and a low dispersion measure $(\mathrm{DPM} \leq 0.3)$.

On the other hand, traditionally, housekeeping genes have been widely used as reference genes due to their ubiquitous expression in different spatial-temporal conditions. However, recent studies show that expression levels of some classic reference genes are not as stable as previously thought $[8,34]$. Here, three housekeeping genes $(U B C, E F 1-\alpha$, and eif4A) were selected to evaluate their suitability as reference genes for qPCR following abiotic stress. $U B C$, an ubiquitin-conjugating enzyme gene, exhibited stable expression in each group examined, whilst the EF1- $\alpha$ was not one of the top three most
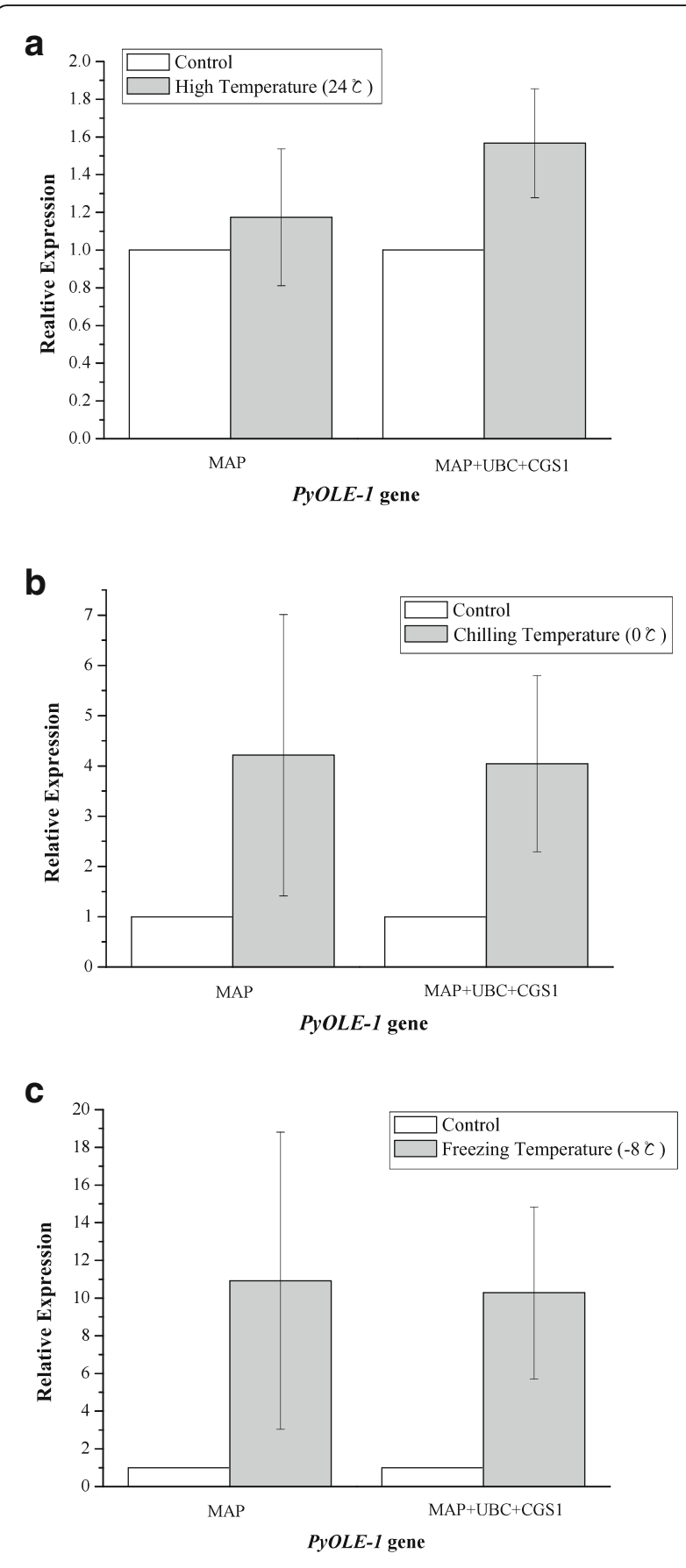

Fig. 4 Comparison of Normalized expression level of PyOLE-1 gene between single and the best reference genes under temperature stress. (a) Relative quantification of PyOLE-1 gene expression using the single reference gene $M A P$ and the best stable reference genes (MAP, UBC and CGS1) under high temperature (a), chilling temperature (b) and freezing temperature (c) respectively. The average $\mathrm{Ct}$ value was calculated from three biological and technical replicates and used for relative expression analyses 


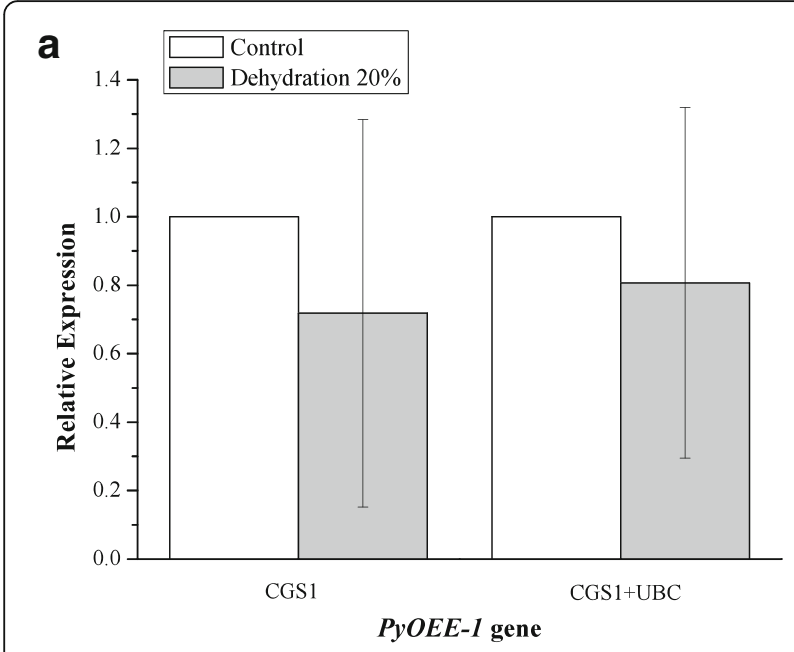

b

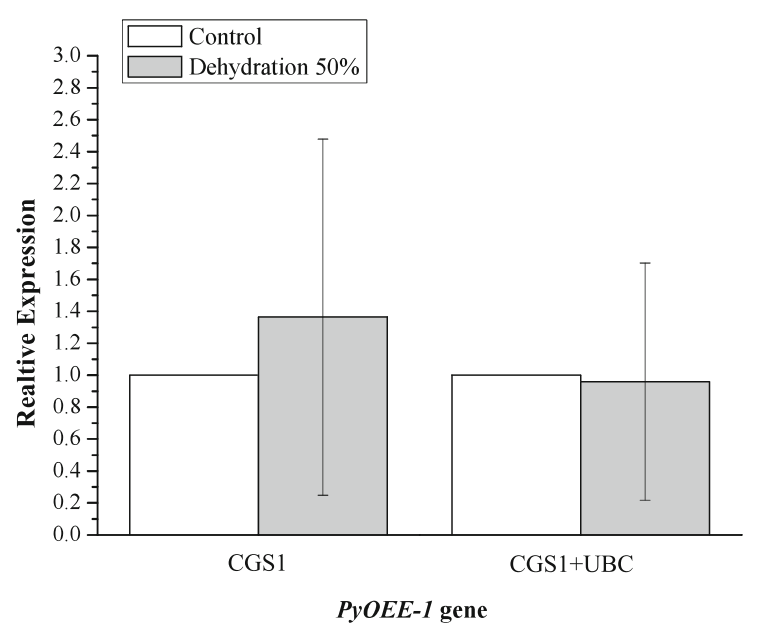

C

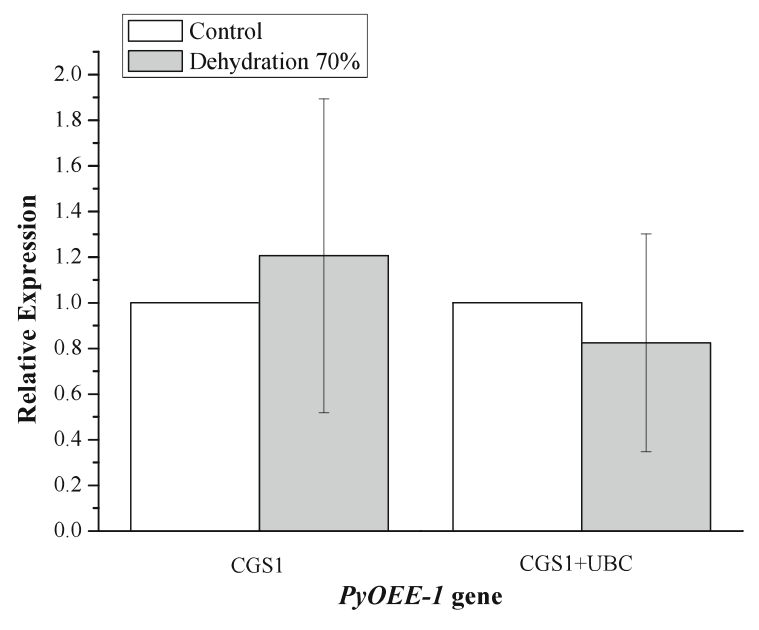

Fig. 5 Comparison of Normalized expression level of PyOEE-1 between single and the best reference genes under dehydration stress. (a) Relative quantification of PyOEE-1 gene expression using the single reference gene CGS1 and the best stable reference genes (CGS1 and UBC) under water loss rate 20\% (A), 50\% (b) and 70\%(c) respectively. The average $\mathrm{Ct}$ value was calculated from three biological and technical replicates and used for relative expression analyses

stable genes in any of the experimental conditions. Nevertheless, eif $4 \mathrm{~A}$ expression was variable in all experimental subsets, and especially in the temperature subset. Therefore, we should take results with some caution when housekeeping genes have been directly used as reference genes for expression normalization in the absence of validation.

Gene expression can be highly tissue-specific and often varies based on the physiological status of the organism or experimental treatments. Therefore, the simultaneous use of several reference genes could decrease the probability of biased normalization $[35,36]$. In addition to identifying the most stable reference genes, geNorm results suggested the optimum pair of genes with the least amount of variation in their expression ratios.

To validate selected reference genes, the relative expression levels of the target genes according to RTqPCR were compared with those derived from RNAseq-based gene expression profiling. As shown in Additional file 2: Figure S2, the RT-qPCR results quantified using best reference genes were more consistent with the RNA-seq-based target genes expression patterns.

Our results also indicated that multiple internal references are necessary for the accurate study of gene expression under various experimental conditions. Indeed, a single reference gene can be insufficient to accurately normalize expression data, or can lead to erroneous interpretation. The optimal number of reference genes required for RT-qPCR analysis has been ongoing discussion [26]. A threshold value of $\mathrm{V}<0.15$ was suggested for normalization. Our results demonstrated that two genes (CGS1 and $U B C$ ) were suitable for normalization under dehydration stress, whilst three genes $(M A P, U B C$, and CGS1) were optimal for temperature stress. In addition, geNorm showed that the V3/4 value was the lowest among all treatment samples but that it was still above 0 . 15. According to several reports, the threshold $\mathrm{V}$ value (pairwise variation) of 0.15 should not be considered as an absolute cutoff but rather a suggested one. Some studies have even reported higher $\mathrm{V}$ values in some species, and the threshold used is thus dependent on a consideration of the research purpose [37, 38]. Considering our results and the practical feasibility, three genes $(U B C, M A P$, and $F H P$ ) were shown to be appropriate for gene expression 
normalization when all samples were analyzed in combination.

Additionally, in order to confirm that our results are more generally applicable across the species, other two genotypes of $P$. yezoensis were treated with the same abiotic stress conditions and the relative expression patterns of PyOLE-1 and PyOEE-1 were then quantified using the best reference and the worst reference genes. We obtained results similar to those obtained for line RZ58, and these results were also consistent with the characteristics of the target genes in algae under abiotic stress (Fig. 6).

\section{Conclusions}

In this study, six candidate genes were selected form the transcriptome of $P$. yezoensis to search several appropriate

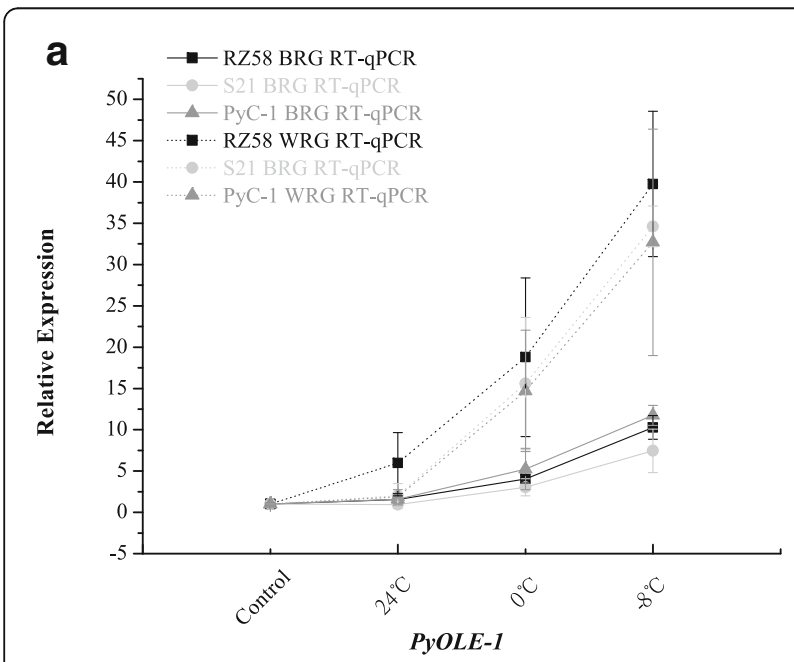

b

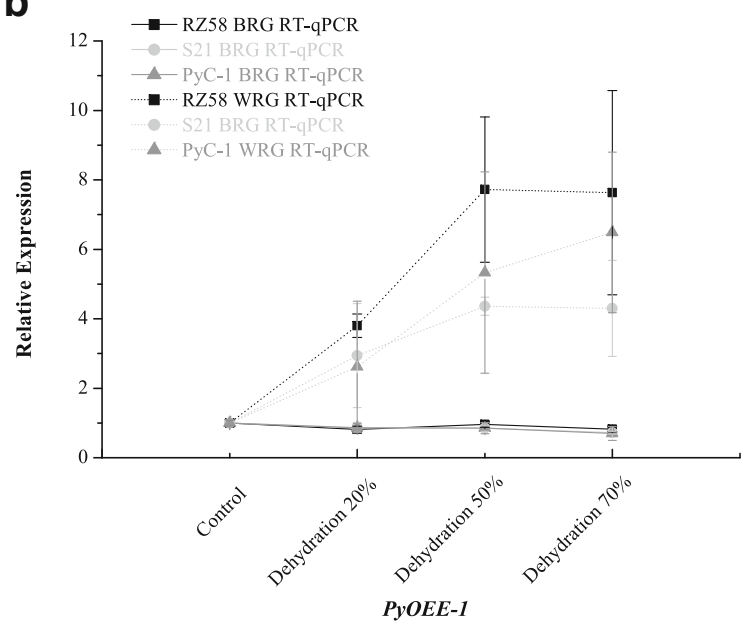

Fig. 6 Comparison of relative expression level of target genes among different genotypes. (a) The relative expression level of PyOLE-1 when using the best (BRG) and the worst reference genes (WRG) in different genotypes (RZ58, S21 and PyC-1). (b) The relative expression level of PyOEE-1 when using the best (BRG) and the worst reference genes (WRG) in different genotypes (RZ58, S21 and PyC-1) reference genes for using in RT-qPCR. And this study also demonstrated that the use of housekeeping genes as reference genes for normalization of expression data should be validated. Based on these results, we identified optimal sets of reference genes to accurately normalize and quantify gene expression under abiotic stress conditions in $P$. yezoensis. We also compared their difference of expression levels between RNA-seq data and RT-qPCR data in different treatments. The result showed that the RNA-seq data is reliable to valuing the expression stability of genes. Further, our results also indicated that multiple reference genes are necessary for accurate study of gene expression in different treatments, such as CGS1 and $U B C$ were suitable for dehydration stress. And, the similarly expression patterns of PyOLE-1 and PyOOE-1 were observed in two other genotypes of $P$. yezoensis confirmed that our identified reference genes more generally applicable across the species. In summary, these reference genes will facilitate further research towards elucidating the molecular mechanisms of stress-tolerance in this economically important species.

\section{Additional files}

Additional file 1: Figure S1. Stability distribution of transcripts using PaGeFinder (PDF $8 \mathrm{~kb}$ )

Additional file 2: Figure S2. Melting curves and agarose gel electrophoresis of PCR products of nine candidate genes. (JPEG $1688 \mathrm{~kb}$ )

Additional file 3: Figure S3. Cycle threshold (Ct) values of nine candidate reference genes across dehydration samples (A) and temperature samples (B). (PDF $194 \mathrm{~kb}$ )

Additional file 4: Figure S4. Expression stability values(M) of nine candidate reference genes calculated geNorm under dehydration (A), temperature (B) and all conditions (C) respectively. (PDF $99 \mathrm{~kb}$ )

Additional file 5: Figure S5. Pairwise variation ( $V$ ) of 9 candidate reference genes. (PDF $104 \mathrm{~kb}$ )

Additional file 6: Table S1. Pairwise variation $(V n / n+1)$ analysis of 9 candidate. (XLSX $10 \mathrm{~kb}$ )

Additional file 7: Figure S6. Three boxplot graphs representing the pairwise differences in the gene expression values of 9 candidate reference genes under all conditions (A), dehydration stress (B) and temperature stress $(C)$ respectively. (PDF $368 \mathrm{~kb}$ )

\section{Abbreviations}

ACT: Actin; CGS1: Cystathionine gamma-synthase 1; CV: Coefficient of variance; DPE2: Disproportionating Enzyme type 2; DPM: Dispersion measure; EF1-a: Elongation factor 1-a; elF4A: Eukaryotic translation initiation factor 4A; FHP: Fumarate hydratase precursor; FPKM: Fragments per kilobase of exon model per million mapped reads; GAPDH: Glyceraldehyde-3-phosphate dehydrogenase; MAP: Methionyl aminopeptidase; M-value: Expression stability value; PPK: Polyphosphate kinase; SD: Standard deviation; SV: Stability value; TUA: a-tubulin; UBC: Ubiquitin-conjugating enzyme

\section{Funding}

This work was supported by the National Natural Science Foundation of China (Grant No. 31372517, 31672641), the Scientific and Technological Innovation Project Financially Supported by Qingdao National Laboratory for Marine Science and Technology (No.2015ASKJ02), the Project of National Infrastructure of Fishery Germplasm Resources (2016DKA30470), Fundamental Research Funds for the Central Universities (201762016, 201562018, 201564009), and the Program for Chinese Outstanding Talents in 
Agriculture Scientific Research. These funding bodies had no role in study design, analysis, decision to publish, or preparation of the manuscript.

\section{Availability of data and materials}

The data sets supporting the results of this article are available in the Sequence Read Archive (SRA) database, accessible through NCBI Bioproject ID PRJNA401493 for the transcriptome data and PRJNA401507 for the expression profile data.

\section{Authors' contributions}

YM conceived and designed the project. DG performed the experiments. DG, FK, and GB analyzed and interpreted the data. YM, DG, FK, and PS drafted and revised the manuscript. All authors read and approved the final manuscript.

\section{Ethics approval and consent to participate}

Plant materials of $P$. yezoensis RZ58 and $P$. yezoensis S21 used in this study were obtained from wild population in Qingdao, Shandong Province, China. And the PyC-1 was provided from a seaweed farm in Rizhao, Shandong Province, China. All samples of these three genotypes were established by clonal cultivation of an isolated single somatic cell and self-fertilization in the laboratory. No field permissions were necessary to collect the plant samples for this study. The authors declared that experimental research works on the plants described in this paper comply with institutional, national and international guidelines.

\section{Competing interests}

The authors declare that they have no competing interests.

\section{Publisher's Note}

Springer Nature remains neutral with regard to jurisdictional claims in published maps and institutional affiliations.

\section{Author details}

'Ministry of Education, Key Laboratory of Marine Genetics and Breeding (Ocean University of China), Qingdao 266003, China. ${ }^{2}$ Laboratory for Marine Biology and Biotechnology, Qingdao National Laboratory for Marine Science and Technology, Qingdao 266237, China. ${ }^{3}$ College of Marine Life Sciences, Ocean University of China, Qingdao 266003, China.

\section{Received: 7 September 2017 Accepted: 3 April 2018}

\section{Published online: 13 April 2018}

\section{References}

1. Sutherland JE, Lindstrom SC, Nelson WA, Brodie J, Lynch MDJ, Hwang MS, Choi H, Miyata M, Kikuchi N, Oliveira MC, Farr T, Neefus C, Mols-Mortensen A, Milstein D, Müller KM. A new look at an ancient order: generic revision of the Bangiales (Rhodophyta). J Phycol. 2011;47(5):1131. https://doi.org/10. 1111/j.1529-8817.2011.01052.x.

2. Blouin NA, Brodie JA, Grossman AC, Xu P, Brawley SH. Porphyra: a marine crop shaped by stress. Trends Plant Sci. 2011;16(1):29-37. https://doi.org/10. 1016/j.tplants.2010.10.004.

3. Huggett J, Dheda K, Bustin S, Zumla A. Real-time RT-PCR normalisation; strategies and considerations. Genes Immun. 2005;6(6):279-84. https://doi. org/10.1038/sj.gene.6364190

4. Kubista M, Andrade JM, Bengtsson M, Forootan A, Jonák J, Lind K, Sindelka R, Sjöback R, Sjögreen B, Strömbom L, Ståhlberg A, Zoric N. The real-time polymerase chain reaction. Mol Asp Med. 2006;27(2-3):95-125. https://doi. org/10.1016/j.mam.2005.12.007.

5. Kim BR, Nam HY, Kim SU, Kim SI, Chang YJ. Normalization of reverse transcription quantitative-PCR with housekeeping genes in rice. Biotechnol Lett. 2003;25(21):1869-72. https://doi.org/10.1023/A:1026298032009.

6. Thellin O, Zorzi W, Lakaye B, De BB, Coumans B, Hennen G, Grisar T, Igout A, Heinen E. Housekeeping genes as internal standards use and limits. J Biotechnol. 1999;75:291-5. https://doi.org/10.1016/S0168-1656(99)00163-7.

7. Goidin D, Mamessier A, Staquet MJ, Schmitt D, Berthiervergnes $O$. Ribosomal 18s RNA prevails over glyceraldehyde-3-phosphate dehydrogenase and beta-actin genes as internal standard for quantitative comparison of mRNA levels in invasive and noninvasive human melanoma cell subpopulations. Anal Biochem. 2001;295(1):17-21. https://doi.org/10. 1006/abio.2001.5171.
8. Radonić A, Thulke S, Mackay IM, Landt O, Siegert W, Nitsche A. Guideline to reference gene selection for quantitative real-time PCR. Biochem Biophys Res Commun. 2004;313(4):856-62. https://doi.org/10.1016/j.bbrc.2003.11.177.

9. Czechowski T, Stitt M, Altmann T, Udvardi MK, Scheible WR. Genome-wide identification and testing of superior reference genes for transcript normalization in Arabidopsis. Plant Physiol. 2005;139(1):5-17. https://doi.org/ 10.1104/pp.105.063743.

10. Lee PD, Sladek R, Greenwood CM, Hudson TJ. Control genes and variability: absence of ubiquitous reference transcripts in diverse mammalian expression studies. Genome Research. 2002;12(2):292. https://doi.org/10. 1101/gr.217802

11. Li L, Yan Y, Xu HX, Qu T, Wang BX. Selection of reference genes for gene expression studies in ultraviolet B-irradiated human skin fibroblasts using quantitative real-time PCR. BMC Mol Biol. 2011;12(1):8. https://doi.org/10. 1186/1471-2199-12-8.

12. Die JV, Roma'n B, Nadal S, González-Verdejo Cl. Evaluation of candidate reference genes for expression studies in Pisum sativum under different experimental conditions. Planta. 2010;232(1):145-53. https://doi.org/10.1007/ s00425-010-1158-1.

13. Wang Z, Gerstein M, Snyder M. RNA-Seq: a revolutionary tool for transcriptomics. Nat Rev Genet. 2009;10:57-63. https://doi.org/10.1002/jnr.21500.

14. Maccoux LJ, Clements DN, Salway F, Day PJ. Identification of new reference genes for the normalisation of canine osteoarthritic joint tissue transcripts from microarray data. BMC Molecular Biology. 2007;8(1):62. https://doi.org/ 10.1186/1471-2199-8-62

15. Ma R, Xu S, Zhao Y, Xia B, Wang R. Selection and validation of appropriate reference genes for quantitative real-time $P C R$ analysis of gene expression in Lycoris aurea. Front Plant Sci. 2016;7(651) https://doi.org/10.3389/fpls.2016.00536.

16. Zhuang H, Fu Y, He W, Wang L, Wei Y. Selection of appropriate reference genes for quantitative real-time PCR in Oxytropis ochrocephala Bunge using transcriptome datasets under abiotic stress treatments. Front Plant Sci. 2015, 6(475):475. https://doi.org/10.3389/fpls.2015.00475.

17. Wu X, Huang A, Xu M, Wang C, Jia Z, Wang G, Niu J. Variation of expression levels of seven housekeeping genes at different life-history stages in Porphyra yezoensis. PLoS One. 2013;8(4):e60740. https://doi.org/10.1371/ journal.pone.0060740.

18. Kong F, Cao M, Sun P, Liu W, Mao Y. Selection of reference genes for gene expression normalization in Pyropia yezoensis, using quantitative real-time PCR. J Appl Phycol. 2015;27(2):1003-10. https://doi.org/10.1007/s10811-014-0359-6.

19. Sun P, Mao Y, Li G, Cao M, Kong F, Wang L, Bi G. Comparative transcriptome profiling of Pyropia yezoensis (Ueda) M.S. Hwang \& H.G. Choi in response to temperature stresses. BMC Genomics. 2015;16(1):1-16. https://doi.org/10.1186/s12864-015-1586-1.

20. Yang H, Mao Y, Kong F, Yang G, Ma F, Wang L. Profiling of the transcriptome of Porphyra yezoensis with Solexa sequencing technology. Chin Sci Bull. 2011; 56(20):2119-30. https://doi.org/10.1007/s11434-011-4546-4

21. Xie C, Li B, Xu Y, Ji D, Chen C. Characterization of the global transcriptome for Pyropia haitanensis (Bangiales, Rhodophyta) and development of cSSR markers. BMC Genomics. 2013;14(1):107. https://doi.org/10.1186/1471-2164-14-107.

22. Alves-Lima C, Cavaçana N, Chaves GAT, Lima NOD, Stefanello E, Colepicolo P, Hotta CT. Reference genes for transcript quantification in Gracilaria tenuistipitata, under drought stress. J Appl Phycology. 2016;29(2):1-10. https://doi.org/10.1007/s10811-016-0896-2.

23. Kim JK, Kraemer GP, Yarish C. Comparison of growth and nitrate uptake by New England Porphyra species from different tidal elevations in relation to desiccation. Phycol Res. 2009;57:152-7. https://doi.org/10. 1111/j.1440-1835.2009.00533.x

24. Li B, Dewey CN. RSEM: accurate transcript quantification from RNA-Seq data with or without a reference genome. BMC Bioinformatics. 2011;12:323. https://doi.org/10.1186/1471-2105-12-323.

25. Pan JB, Hu SC, Wang H, Zou Q, Ji ZL. PaGeFinder: quantitative identification of spatiotemporal pattern genes. Bioinformatics. 2012:28(11):1544-5. https:// doi.org/10.1093/bioinformatics/bts169.

26. Vandesompele J, De PK, Pattyn F, Poppe B, Van RN, De Paepe A, Speleman F. Accurate normalization of real-time quantitative RT-PCR data by geometric averaging of multiple internal control genes. Genome Biol. 2002;3:1-11. https://doi.org/10.1186/gb-2002-3-7research0034

27. Andersen $\mathrm{CL}$, Jensen $\mathrm{J}$, Orntoft TF. Normalization of real-time quantitative reverse transcription-PCR data: a model-based variance estimation approach to identify genes suited for normalization, applied 
to bladder and colon cancer datasets. Cancer Res. 2004;64:5245-50. https://doi.org/10.1158/0008- 5472.CAN-04-0496.

28. Pfaffl MW, Tichopad A, Prgomet C, Neuvians TP. Determination of stable housekeeping genes, differentially regulated target genes and sample integrity: BestKeeper - excel-based tool using pair-wise correlations. Biotechnol Lett. 2004;26(6):509-15. https://doi.org/10.1023/B: BILE.0000019559.84305.47.

29. Silver N, Best S, Jiang J, Thein SL. Selection of housekeeping genes for gene expression studies in human reticulocytes using real-time PCR. BMC Mol Biol. 2006;7:33. https://doi.org/10.1186/1471-2199-7-33.

30. Xie $\mathrm{FL}$, Xiao $\mathrm{P}$, Chen $\mathrm{DL}$, Xu L, Zhang BH. miRDeepFinder : a miRNA analysis tool for deep sequencing of plant small RNAs. Plant Mol Biol. 2012;80:75-84. https://doi.org/10.1007/s11103-012-9885-2.

31. Hellemans J, Mortier G, Paepe AD, Speleman F, Vandesompele J. qBase relative quantification framework and software for management and automated analysis of real-time quantitative PCR data. Genome Biol. 2007; 8(2):R19. https://doi.org/10.1186/gb-2007-8-2-r19.

32. Hua CW, Soler M, Yu H, Camargo ELO, Carocha V, Ladouce N, Savelli B, Paiva JAP, Leple JC, Pettenati JG. Reference genes for high-throughput quantitative reverse transcription-PCR analysis of gene expression in organs and tissues of Eucalyptus grown in various environmental conditions. Plant Cell Physiol. 2012;53:2101-16. https://doi.org/10.1093/pcp/pcs152.

33. Yang H, Liu J, Huang S, Guo T, Deng L, Hua W. Selection and evaluation of novel reference genes for quantitative reverse transcription PCR (qRT-PCR) based on genome and transcriptome data in Brassica napus L. Gene. 2014; 538(1):113-22. https://doi.org/10.1016/.gene.2013.12.057.

34. Stitt M, Altmann T, Udvardi MK, Scheible WR. Genome-wide identification and testing of superior reference genes for transcript normalization in Arabidopsis. Plant Physiol. 2005;139(1):5-17. https://doi.org/10.1104/pp.105.063743.

35. Gutierrez L, Mauriat M, Pelloux J, Bellini C, Van WO. Towards a systematic validation of references in real-time RT-PCR. Plant Cell. 2008;20:1734-5. https://doi.org/10.1105/tpc.108.059774.

36. Schmittgen TD, Zakrajsek BA. Effect of experimental treatment on housekeeping gene expression: validation by real-time, quantitative RTPCR. J Biochem Biophys Methods. 2000;46:69-81. https://doi.org/10. 1016/S0165-022X(00)00129-9.

37. De KA, Goossens K, Peelman L, Burvenich C. Technical note: validation of internal control genes for gene expression analysis in bovine polymorphonuclear leukocytes. J Dairy Sci. 2006;89(10):4066-9. https://doi. org/10.3168/jds.S0022-0302(06)72450-X.

38. Wan H, Zhao Z, Qian C, Sui Y, Malik AA, Chen J. Selection of appropriate reference genes for gene expression studies by quantitative real- time polymerase chain reaction in cucumber. Anal Biochem. 2010;399:257-61. https://doi.org/10.1016/j.ab.2009.12.008.

\section{Ready to submit your research? Choose BMC and benefit from:}

- fast, convenient online submission

- thorough peer review by experienced researchers in your field

- rapid publication on acceptance

- support for research data, including large and complex data types

- gold Open Access which fosters wider collaboration and increased citations

- maximum visibility for your research: over $100 \mathrm{M}$ website views per year

At BMC, research is always in progress.

Learn more biomedcentral.com/submissions 